\title{
A ETERNIDADE DA MENTE EM ESPINOSA: A SALVAÇÁO DE UM EXCOMUNGADO
}

\author{
Philippe Alcantara Gebara Tavares ${ }^{1}$
}

Resumo: Uma das mais importantes teses de Espinosa é o paralelismo, particularmente entre o corpo e a alma. Tudo o que se passa com o corpo deve corresponder com eventos na alma. Assim, ao morrer o corpo, a alma cessaria também de existir. "Mas uma melhor parte da mente permanece" - afirmará o filósofo, de forma surpreendente. Percorremos as interpretaçóes de Steven Nadler e de Donald Rutheford, uma de enfoque mais metafísico e outra, mais afetivo, buscando compreender mais dessa intrigante doutrina de Espinosa, que póe em suspenso a possibilidade de salvação ao homem.

Palavras-chave: eternidade da mente, identidade pessoal, acquiescentia animi.

Abstract: One of the most important Spinoza's theses is the parallelism, mainly between soul and body. Everything which happens with the body should correspond with events in the soul. Dying the body, thus, the soul would cease also to exist. "But a better part of the mind remains"

- the philosopher will affirm, in an astonishing way. We go through the interpretations of Steven Nadler and Donald Rutheford, one of a more metaphysical approach and other of a more affective approach, to try to understand more about. It is a puzzling doctrine of Spinoza, which puts on hold the possibility of man's salvation.

Keywords: eternity of mind, personal identity, acquiescentia animi.

\footnotetext{
${ }^{1}$ Graduado em Filosofia pela UFRJ. Email: gebara@gmail.com 


\section{Introdução}

A excomunháo de Espinosa pela comunidade judaica em 1656 teria acontecido, segundo Steven Nadler, porque o filósofo "defendia teses "cartesianas" com o agravante de questionar a imortalidade da alma” (PINHEIRO, 2011). Mas diferentemente disso, Descartes se orgulhava por sua filosofia trazer felizes consequências para a religiáo (NADLER, 2002, 224p), da qual a subsistência e a imortalidade da alma sáo exemplos, derivados do dualismo alma-corpo. Assim, Espinosa, ao questionar a imortalidade da alma e defender a identidade entre a alma e corpo, teria assumido uma tese mais radical do que Descartes, posicionando-se realmente contra o pensamento religioso tradicional. No entanto, o filósofo holandês, em seu Curto Tratado, trata da "imortalidade da alma” no Capítulo 23 (PINHEIRO, 2011). De fato, Espinosa parece algumas vezes expressar opinióes ambíguas com relação ao tema da vida após a morte, particularmente na Parte V da Ética, que trata da parte eterna da mente que permanece após a destruiçáo do corpo. Nela aparece uma defesa da eternidade da mente que poderia muito bem ser confundida com a da imortalidade da alma. Em alguns sistemas, de fato, mente, alma, imortalidade e eternidade são identificadas entre si, mas, como pretenderemos mostrar, não no de Espinosa.

De tal esclarecimento, vai depender o estatuto da salvaçáo, que seria o principal objetivo de uma ética, a qual propõe meios para se chegar à felicidade. Em verdade, Espinosa entende que a felicidade não depende de fazer o que se imediatamente deseja, à mercê das circunstâncias da vida. Ao contrário, eticamente estabelece um meio claro - o exercício do entendimento para se ao menos alcançar, em suas palavras, a satisfaçáo consigo mesmo: a acquiescentia in se ipso. Um afeto que nos traria uma "salvação secular", na expressáo de Yovel: um "estado a ser alcançado dentro desta vida, e não depois dela. Seja o que for essa salvação, ela enriquece a existência imanente e terrena do filósofo. Sem ter nenhuma importância além" (in RUTHEFORD, 1999, 449p).

Mas, além do mundo terreno, Espinosa também falará de uma felicidade eterna, saindo a princípio de uma esfera pagã para se aproximar de uma esfera religiosa, dentro dos avanços e retrocessos em relação à tradição que apresenta. 
A tal felicidade eterna ele chamará de "beatitude". Para atingi-la, o meio a ser perseguido é o $3^{\circ}$ gênero de conhecimento: "um conhecimento intuitivo pelo qual apreendemos a dependência necessária e eterna das coisas finitas na essência infinita de Deus" (RUTHERFORD, 1999, 447p). E como, em Espinosa, "todo estado epistêmico sempre envolve um afetivo" (Idem), o $3^{\circ}$ gênero é acompanhado de afetos, que são o amor intelectual a Deus e a suprema satisfação (summa acquiescentia, também chamada de acquiescentia animi).

Segundo Ronald Rutherford, os comentadores só se concentraram no afeto do amor intelectual a Deus, deixando de lado a associaçáo que existe entre acquiescentia animi e beatitude, o que faria parte de uma teoria ética mais ampla (Idem).

Estudando em que consiste a eternidade da mente, bem como avaliando a pertinência de cada salvaçáo, secular ou eterna, ao usar, como propóe Rutherford, os conceitos relacionados à satisfaçáo (acquiescentia in se ipso e acquiescentia animi), cercaremos o problema de dois lados, primeiro sob um olhar mais metafísico, de acordo com os comentários de Nadler, e depois sob um olhar mais afetivo, segundo os de Rutherford. Assim, esperamos trazer algumas luzes para a compreensão do principal objetivo da Ética de Espinosa.

\section{Apresentaçáo da filosofia da Ética}

Antes de prosseguirmos com a questão do estudo, que se encontra na última parte da Ética, é preciso apresentar as principais teses das partes restantes, das quais a nossa questão é consequência.

O pilar do projeto espinosista é a radicalizaçáo do conceito de substância, tal como era entendido por muitos autores da tradição. Para estes, a substância era o que é por si: aquilo cuja essência não depende de outro para ser atualizada, em oposição ao acidente. Tinham, porém, em mente que esse era um conceito analógico porque, ao ser restritamente considerado, só se aplicaria a Deus, visto que as coisas do mundo náo seriam, no fim, autônomas, mas dependeriam desse ipsum Esse subsistens ${ }^{2}$ para existir. Para marcar bem essa diferença e evitar qualquer ambigüidade, tais autores atribuíram a Deus o qualificativo "em si”, indicando sua subsistência absoluta. Contudo, Espinosa está preocupado em propor um sistema bem claro,

\footnotetext{
${ }^{2}$ Do latim, "o próprio Ser subsistente".
} 
com definições precisas, onde não há lugar para variações analógicas. Para se delimitar um conceito, é preciso saber as regras de produçáo do objeto a que corresponde. Só posso conhecer conceitualmente um círculo se conheço sua gênese (que segue de uma linha traçada de forma equidistante em torno de um centro). Assim, o conceito de substância - o que não depende de nada para existir e de nada para ser concebido - náo poderia se referir a nada além do que Deus, pois é sua regra de geração. Não há substâncias segundas: todos os entes são como que acidentes da única substância, que é Deus, mas não como entidades que lhe são acrescidas de forma extrínseca, mas como entidades que por ela são geradas. Por isso, em vez de "acidentes", Espinosa preferiu o termo "modos" para designar essas afecções da substância.

A substância (...), portanto, é um ser único que se expressa em diversas formas, ser infragmentável porém matizado, infinitamente diferenciado sem ser descontínuo, e produzindo necessariamente em si uma infinidade de coisas naturais finitas que não mais são do que seus modos (GLEIZER, 2005, 18p).

"Ou Deus, ou Natureza" - é a opção que o filósofo nos oferece para apontar a essa realidade que tudo engloba. Não existe um ser pessoal, inteligente, que cria e governa o mundo, recompensando cada um de acordo com suas obras. Deus é imanente ao nosso mundo, mas náo se esgota nele. A realidade que conhecemos é apenas uma produçáo da Natureza, desse Deus, sob os atributos da Extensão e Pensamento. Como fomos feitos dentro dessas duas expressões ou atributos de Deus, sendo parcelas de extensão que pensam, só podemos conhecer a realidade dentro desses limites de Extensão e Pensamento. Mas os atributos da Natureza são infinitos e, como Espinosa demonstra, não há comunicação entre nenhum deles (corpo e alma, por exemplo, estáo isolados em suas respectivas afecçóes e ideias). Mesmo sendo infinitamente "totipotente", Deus consegue se esgotar produzindo todos os modos possíveis, de acordo com cada atributo, porque sua essência é pura potência ativa (pura enérgeia, em termos aristotélicos). Ele caracteriza-se por ser, de fato, tudo que pode ser. Por isso, $\underline{e}$ todo o possível, gerando-o através de modos, não por uma vontade livre, mas por uma implicação lógico-matemática independente:

O conceito de potência náo designa em Espinosa uma virtualidade cuja atualizaçáo seria contingente, mas sim uma atividade causal inesgotável na qual a substância é determinada exclusivamente por sua própria 
essência a produzir nela mesma infinitas coisas em infinitos modos, isto é, tudo que é concebível (Idem).

A produção dos modos pode ocorrer de duas formas: (i) seguindo diretamente da natureza de Deus, ou (ii) através da influência de outros modos. A essência de Deus, em si mesma considerada, modifica-se e produz as essências eternas dos entes finitos. Mas a atualização desses modos eternos no espaço e no tempo depende dos encontros dos entes atuais, de acordo com a ordem da Natureza.

Em um horizonte onde toda possibilidade é atualizada, não há espaço para a liberdade de escolha, para um ser diferente. Tudo, que existe assim, existe porque deveria ser assim. A necessidade preenche todos os entes e acontecimentos. O homem apenas crê ter livre-arbítrio e o mal perde seu escopo metafísico, tornando-se relativo a cada indivíduo.

Todas as teses metafísicas que apresentamos até agora são estabelecidas, de modo geral, na Parte I da Ética, preparando terreno para a exposição de uma antropologia filosófica, que é revolucionária, na Parte II. O homem deixa de ser composto, tal como ocorria no cartesianismo, por duas substâncias diferentes, corpo e alma, misteriosamente unidas, para ser uma só realidade, que pode ser expressa de duas formas: ou através do Pensamento, como alma, ou da Extensáo, como corpo. Como dissemos, os atributos são independentes, mas Espinosa propóe de forma sofisticada que há um paralelismo entre seus eventos. Cada vez que eu tiver uma dada afecção corporal, terei uma ideia correspondente. Essa relação afecção-ideia se manterá para toda a ordem (ou sucessáo) de causas de cada atributo. O nexo causal é sempre o mesmo, pois, remetendo à única substância onde tudo se move, o que se passa em um atributo é, no fundo, a mesma realidade que se passa no outro atributo. Por exemplo, a ideia 1, correspondente à afecção 1 , sempre será seguida da ideia 2 , correspondente à afecção 2 , da mesma forma que entre afecção 1 e da afecção 2 há também uma relação permanente de sucessão. De forma bem específica, o filósofo expressa na antropologia esse paralelismo entre atributos definindo a alma como ideia do corpo, superando a separação total:

E isso permite a Spinoza explicar o conhecimento do mundo corpóreo muito mais facilmente do que Descartes conseguiu. A mens é, de fato, para Spinoza, originariamente consciência do corpo; portanto, se apercebe das modificaçôes dele, e por meio dessas modificaçóes 
conhece, mesmo que indiretamente, os outros corpos (ROVIGHI, 2006).

Conhecer através das afecções pertence ao $1^{\circ}$ gênero de conhecimento que propóe o filósofo, caracterizado pela imaginação, que é fonte de engano. Clareza e distinção só terá o homem através do $2^{\circ}$ gênero, por meio das noçóes comuns, usando a razão; e através do $3^{\circ}$ gênero, por meio das essências singulares, apreendidas pela intuiçáo. Mais à frente deter-nosemos melhor em tais gêneros de conhecimento.

Passemos agora à afetividade espinosista, ligada às modificaçóes do corpo, tema da Parte III. Espinosa concebe o afeto como a afecção do corpo que aumenta ou diminui nossa potência de agir, acompanhada da ideia dessa afecção. Uma concepção que oscila "entre o modo cartesiano de considerar [o afeto] como conhecimento confuso e o conceito escolástico [de afeto] como tendência, impulso sensitivo"3. Ora, o filósofo assimila potência à essência: o que caracteriza cada ente é a maneira com que pode atuar, de acordo com sua participação na potência de Deus. Nem sempre a coisa exerce sua potência, pois pode ser impedida por outros, mas mesmo assim ela persiste. Por isso, seu impulso por perseverar em seu ser ganha o nome de "esforço" (conatus). O homem esforça-se por conhecer. Ao deixar-se afetar por causas exteriores, pode ou não ter sua potência de pensar aumentada (note-se a estrita co-pertinência de epistemologia e afetividade). Seja de uma forma ou outra, como está em posição passiva, o que lhe afeta tem o nome de paixóes. Quando sofre diminuição de potência, por uma paixão desfavorável, sendo afetado de tristeza, náo consegue representar de forma adequada/ verdadeira a realidade (influência cartesiana). Porém, ao agir de forma autodeterminante, realiza açôes, e náo padece. Conhece de fato e é certamente afetado de alegria, pois sua potência é aumentada (influência escolástica). A partir dessa mecânica básica, uma árvore inteira de afetos será engendrada, incluindo amor, ódio, ciúme, compaixão, inveja, cobiça, etc.

Como viver eticamente? A Parte IV discursa sobre a virtude, identificando-a com o esforço. Ao agir de forma virtuosa, seguindo uma conduta em vista da felicidade, o homem não busca nada mais do que sua conservação, ou seja, esforça-se. A virtude, em outras palavras, tem em vista o que nos é útil, os afetos bons, para contrabalancear os afetos maus.

\footnotetext{
${ }^{3}$ Idem, 195p. Substituímos a "paixão" da tradução por “afeto", pois paixão é um afeto passivo. 
O instrumento para chegar a tal relação orientada para o que aumenta nossa potência é proposto pela Parte V como a razáo. Por ela, compreendemos que tudo é necessário, pois as coisas são modos da única substância, de Deus. Assim, conhecemos no nível mais profundo a realidade. Um conhecimento tão excelente só pode nos causar máxima alegria, pois satisfaz soberanamente nosso desejo por conhecer. Sendo Deus a causa dessa alegria suprema, passamos a amá-lo, isto é, a amar todas as coisas, que lhe são modos, de uma forma igual, deixando de amar ou odiar apenas uma coisa ou outra. Numa segunda seção da Parte V, Espinosa passa a considerar o que sucede, depois da morte, à vida presente, chegando ao nosso tema de estudo.

\section{Eternidade-imortalidade}

Começando a adentrar no problema: Que é o tempo? Como medi-lo? Para Espinosa, ele depende da existência dos modos finitos. Se algo existe agora, e não é em si, em um momento começou a existir por uma causa eficiente. Entre essas duas referências - uma no passado, em um início de existência, e uma no presente, no que vejo agora - supóe-se uma continuidade. Isso é o que o filósofo chama de duração: a continuação no existir a partir de um começo. Ao entrar na existência, a essência do modo é determinada a perseverar no existir. Ela náo envolve nenhuma noção de término, porque é, por si, ilimitada. Que um modo tenha um fim, dependerá da ação de causas exteriores. "A morte e o nascimento não são de modo algum simétricos" (DELEUZE, 2002, 69p). Já a eternidade, que está fora do tempo, é a existência de algo eterno, porque concebido como necessário (IDef84), sem começo. Ora, obviamente um modo, depois da morte, não poderia entrar na eternidade, como em uma sequência de fatos. Tal seria o caso de passar à imortalidade para as religióes tradicionais, de acordo com a interpretaçáo que Espinosa faz delas.

\footnotetext{
${ }^{4}$ As citaçóes da Ética são retiradas da tradução de Tomaz Tadeu, seguindo este modelo: número da Parte em algarismos romanos; Proposição abreviada por "P", com sua referência em algarismos indoarábicos; escólio abreviado por "s"; corolário, por "c"; definição de afetos, por “aff. def.”; apêndices, por "app.”.
} 
Eterno seria Deus, seus atributos da Extensão e Pensamento e os modos infinitos (como a lei do movimento e repouso). E também poderiam ser coisas finitas, consideradas enquanto produzidas diretamente por Deus, em suas essências.

\section{Interpretação de Steven Nadler}

\subsection{Panorama sobre a eternidade da mente}

Muitos julgaram que a famosa Proposição 7 da Parte II da Ética, na qual o "dualismo cartesiano entre alma e corpo é aparentemente negado" (PINHEIRO, 2011), propunha que, cessando de existir o corpo, cessaria de existir também a mente, junto com alma, pois o corpo, no sistema espinosista, não só se relaciona com a alma por uma relação de representação, mas de identidade 5 . Esses, que assim compreenderam o assunto, ao chegar na Parte V da obra, na qual se afirma que "[a]s reflexôes que precedem terminam o que tinha o propósito de dizer sobre a vida presente. [....] É chegado, pois, o momento de passar a considerar o que pertence à duraçáo da mente sem relaçáo com o corpo" (VP20s), consideram muitas vezes que Espinosa entrou em contradição. Chegam mesmo, como Jonathan Bennett, a tomar essa Parte como um "absoluto e aparentemente desmotivado desastre... lixo que leva outros a escrever lixo" (BENNETT, 1984, 357p). No entanto, a defesa da eternidade da mente não é em absoluto "desmotivada", pois está em profunda ligação não só com proposições da Ética, mas com o fim dela mesmo, que é levar os homens a uma vida ética (e isso o próprio Espinosa afirma no Escólio acima citado). De fato, segundo Nadler, Bennett “ou está intencionalmente exagerando para dar apoio a seus argumentos, ou falha em compreender a importância do inteiro trabalho" (NADLER, 2001, 225p).

O cenário ainda piora quando Espinosa diz que apenas a "melhor parte" da mente sobrevive à morte do corpo. O que seria ela e se envolve identidade pessoal é um assunto de grande debate. Edwin Curley, ausentando-se de esclarecer sua natureza, sentencia que a doutrina da eternidade da mente de forma alguma significará que "eu possa cogitar ter qualquer esperança

5 É uma conclusão derivada dos seguintes enunciados: (1) “...um modo da extensão e a ideia desse modo é uma só e mesma coisa, mas expressa de duas maneiras" (IIP7s.) (2) "O objeto da ideia que constitui a alma humana é o corpo" (IIP13). 
de imortalidade” (Idem). James Morrison explicará essa negação da identidade, apresentando que é o corpo a condição essencial de individuaçáo (indo ao encontro dos partidários da inexistência de vida pós-morte, a que inicialmente nos referimos). Também rejeitando a identidade pessoal, mas dando um passo a mais, Stuart Hampshire ousa explicar que a existência que a mente passa a gozar é de estar unida a "Deus ou Natureza concebidos sob o atributo do Pensamento", uma teoria que Nadler considera de tipo averroísta (Idem).

Mas ainda restarão aqueles que defendem a imortalidade pessoal, em uma interpretação "mais popular", sendo uma de suas posiçóes a que atribui à "melhor parte" justamente a pessoalidade, e outra posição, chamada de "aristotélica" (Idem), que a considera como sendo a forma do corpo.

Entretanto, como Nadler observa, Espinosa nunca usa o termo immortalitas como conceito de seu sistema; utiliza-o apenas uma vez, quando está falando sobre a falsa crença da multidão no céu e inferno. $\mathrm{O}$ vulgo a usaria, de forma muito freqüente, como desculpa para agir moralmente, na esperança em obter, depois da morte, um preço por sua servidáo, e do medo de ser punido com cruéis suplícios. Do contrário, se tais realidades não existissem, entregar-se-ia à licenciosidade, em vez de renunciar a seus direitos em prol de um direito divino. Mas isso, para o filósofo holandês, é tão absurdo quanto alguém que, "por náo acreditar que possa, sempre, alimentar seu corpo com bons alimentos, preferisse saciar-se de venenos ou substâncias letais" (VP41s). A virtude vale a pena por si só: que o estado de satisfação não continue depois da morte, não quer dizer que não devamos persegui-lo nesta vida.

Esse é um dos elementos que levam Espinosa a rejeitar a imortalidade da alma, o que faz com "absoluta satisfação" (Idem, 228p), porque quer homens felizes, não homens inquietos por imagens (ideias confusas).

\subsection{Dois aspectos da eternidade da mente}

A eternidade que o filósofo confere à mente, enquanto é a ideia do corpo, pode ser vista sob dois aspectos. Há uma eternidade que a alma de todo ser tem, e outra especificamente da mente humana. 
Em primeiro lugar, em ocasião da morte, a mente passa a não exprimir mais a existência atual do corpo (VP21), como fazia quando ele existia. Ora, tal "expressão" definia o ser atual da mente, na medida em que a mente consistia em uma idéia cujo objeto era o corpo (IIP11 e IIP13). Pelo ax. 6 da P.1, uma ideia supóe sempre um objeto (ideado). Assim, ao cessar de existir o corpo, a ideia que era a mente, sem seu objeto, cessaria também de existir? Não, pois "a mente humana náo pode ser inteiramente destruída juntamente com o corpo: dela permanece algo que é eterno", de acordo com a prop. 23 da Parte V. Que algo é este? Como Espinosa demonstra, existe em Deus a ideia da essência do corpo humano, concebida, não pela duraçáo, mas por uma necessidade eterna, em virtude da própria essência de Deus. Apontando à prop. 13 da Parte II, o filósofo tenta atrelar tal ideia de essência do corpo à essência da mente, mas essa proposição excluía justamente tudo que constituísse o objeto da mente além do corpo existente. A soluçáo possível seria que Espinosa resgata a definiçáo da prop. 13, de que o objeto da ideia que constitui mente é o corpo, para lhe dar nova significação, a partir da nova perspectiva que introduz na Parte V: a da eternidade. Portanto, o corpo, considerado em sua essência, seria o objeto da mente, igualmente considerada. Uma parte, pois, da mente subsistiria à morte: sua essência, que é eterna.

O acima exposto náo é exclusividade do homem. "Tudo o que dissemos da ideia do corpo humano deve-se necessariamente dizer-se da ideia de qualquer coisa" (IIP13s). Todo ser é uma modificação do atributo da Extensáo, uma quantidade extensional, definida por uma razáo eterna entre movimento e repouso de partes infinitamente pequenas (embora a organizaçáo do corpo humano seja bem mais complexa). Essa razão é sua essência sob o aspecto da Extensão: uma possibilidade eterna de esse atributo ser modificado. Pela lei do paralelismo, onde tudo que pertence à ordem dos corpos pertence também à ordem das ideias, há uma modificaçáo correspondente do atributo do Pensamento: uma ideia que exprime a essência da mente, relativa a tal parte eterna do corpo. Portanto, a existência eterna de uma essência da mente não é particular ao homem, nem possui ligaçáo com a vida na duraçáo. Essa essência não inclui pessoalidade.

Já que até aqui parece náo haver esperança para o homem preocupado com o além, passemos para o segundo lugar. 
Agora trataremos da estranha parte da mente que, de acordo com a prop. 38 da Parte V, é suscetível a aumento, na medida em que, pelo $2^{\circ}$ e $3^{\circ}$ gêneros de conhecimento, diminui o padecimento que sofre.

A essência de toda coisa é perseverar em seu ser. Disso depende a virtude, para o homem, que consiste em buscar tudo que lhe é útil. Ora, o corpo humano tem como função particular o compreender. Logo, o conhecimento lhe é útil para continuar existindo como ser cognoscente.

No entanto, nem todo conhecimento dá o homem um quadro fiel da realidade. Há aquele inadequado, que vem dos sentidos, que mais representam seu corpo afetado do que o objeto que modifica. É um conhecimento circunscrito às "limitaçôes perceptivas de seu [do corpo] lugar físico" (NADLER, 2002, 233p), dependendo da "ordem comum da natureza", dos encontros que o corpo terá ao acaso com outros corpos. É um conteúdo que é objeto da imaginação, na peculiar concepção de Espinosa, que caracteriza o $1^{\circ}$ gênero de conhecimento. A imagem é necessariamente "confusa e mutilada" (IIP29c), pois não traz conhecimento das essências das coisas; este apenas a ideia adequada oferecerá.

Só o $2^{\circ}$ e $3^{o}$ gêneros trarão um conhecimento verdadeiro da natureza, racional e ordenado. $\mathrm{O} 2^{\circ}$ gênero depende da razão e o $3^{\circ}$, diretamente de uma “intuiçáa”". A razáo alcança ideias adequadas através de um raciocínio, de um método discursivo. Descobre, em último caso, que todas as coisas estáo ligadas causalmente aos atributos de Deus. Isso é descobrir suas essências; ou como modificação particular da Extensão ou como modificaçáo particular do Pensamento. Dessa forma, o homem compreende as coisas e a ordem da natureza como necessárias, como parte do próprio Deus eterno, em uma concepção fora do tempo, sob perspectiva da eternidade. Assim, ele não padece refém do mundo, mas atua.

Já pelo $3^{\circ}$ gênero de conhecimento, a mente consegue compreender tudo isso só por um ato, prescindindo de premissas. É um conhecimento mais excelente, pois náo depende da duraçáo, de outros corpos. A mente que o executa está desempenhando seu maior poder ou virtude, realizando-se como ser racional e cumprindo sua essência.

Se as ideias adequadas em jogo revelam as verdades necessárias do universo, elas são eternas. Subsistem à morte do corpo e compóem a parte da mente que permanece. Assim, quanto maior for o número de ideias adequadas que obtivermos, maior será a parte eterna de nossa mente e maior nossa "participação" na eternidade, na expressão de Nadler, desde agora 
(Idem, 237p). Desse modo, menos temeremos a morte, porque menos seremos afetados de afetos nocivos (VP38). O medo, por exemplo, é um deles, sendo uma "tristeza instável, surgida da ideia de uma coisa futura ou passada, de cuja realizaçáo temos alguma dúvida" (III aff. def. 13). Da morte, não podemos ter dúvida, porque o esforço da Natureza sempre superará o nosso, mas há nela, de fato, uma dúvida envolvida. Pensamos que ela pode ser condição para algo que a suceda de que não temos certeza, causando-nos dúvida, medo e tristeza. Contudo, se já sentirmos e experimentarmos que somos eternos por "participação" neste mundo, gozaremos de suma satisfação e afastaremos as paixóes más, como o medo.

Porém, depois da morte, só restando ideias adequadas, "algo que pertenceu a mim e compôs uma parte - a parte eterna - dos conteúdos da minha mente" (Idem), não haverá continuação de pessoalidade, pois esta supóe consciência de ser o mesmo ente continuando a existir, através da memória, que é uma função do corpo, dependente da duração.

\subsection{Possível referência da parte eterna da mente à pessoa que a possuiu}

Se está claro que a pessoa não continua depois da morte, resta a questáo se poderia ainda haver, na parte eterna da mente que permanece, algo que a identificasse como tendo feito parte de tal ou tal pessoa na duração. O nosso leitor atento logo perceberá que isso parece ser uma contradição em termos, pois a eternidade não carrega nenhuma referência à duraçáo. Entretanto, fechar essa porta logo nos levará à conclusão de que não há como distinguir qualitativamente uma mente de outra na eternidade, negando aparentemente a permanência da parte eterna de uma mente, depois da morte.

Para Harry A. Wolfson, a distinção que supóe existir entre mentes eternas se realizaria pela quantidade de ideias adequadas que cada uma, durante o fluxo da vida, conseguiu obter (Idem, 239p). Mas e se obtivessem o exato número de ideias adequadas, se estamos falando em termos quantitativos? Aquele não parece ser, portanto, um critério suficiente de distinção.

Além do aspecto eterno da mente ligado a essa coleção de ideias, é preciso lembrar daquele que a define, assim como as mentes de outros seres, como expressáo no atributo do Pensamento da essência do corpo. Pensando que cada indivíduo é único, composto por diferentes partes infinitamente pequenas, segundo uma razáo entre o movimento e repouso 
destas, que traduz sua essência, esse poderia ser um bom critério de identidade. Contudo, para Nadler, o exemplo dos gêmeos perfeitamente idênticos, os quais teriam uma igual essência, rompe com essa possibilidade (Idem, 242p). Possibilidade que ele considerava a última para salvaguardar a identidade da mente eterna, chegando à conclusáo de que as ideias adequadas e a ideia da essência do corpo, depois da morte, simplesmente se dispersam e retornam ao intelecto infinito de Deus. Isso acontece pois essas ideias, sendo modos do atributo do Pensamento, que, reunindo-se, formam o intelecto de Deus, não são nada mais que o conhecimento que Deus tem das coisas.

Nesse ponto, Nadler admite estar confuso sobre a integridade da "coleção" de ideias adequadas que constituem uma mente eterna. Como a ideia adequada, por exemplo, de um cachorro poderá estar em dois indivíduos ao mesmo tempo? Mas o autor explica que, se sua tese estiver correta, há uma só da "coleção" de ideias adequadas, da qual as mentes usufruem na duração, levando-as a "participar" da eternidade. Desse transcender o tempo durante alguns instantes de nossa vida, podemos ser plenamente conscientes e, assim, gozar de suma alegria. $\mathrm{Na}$ eternidade, não teremos pessoalidade, nem ao menos identidade.

\subsection{Rejeiçáo da imortalidade na obra para fins morais e políticos}

Mesmo que náo estejamos convencidos sobre em que consiste a eternidade da mente, para Nadler, uma coisa é certa: Espinosa rejeita a imortalidade da alma, por seus argumentos contra a religiáo. Mais especificamente, por combater a manipulação dos líderes religiosos, a qual se baseia principalmente na exploraçáo dos afetos de medo e esperança dos crentes em relaçáo à vida eterna, para ganhar poder. Solapando esse fundamento de persuasáo, Espinosa quer nos liberar das paixóes más e abrir espaço para uma vida de bem-estar, sob a condução da razão.

Portanto, mais que uma tese metafísica, o filósofo quer trazer uma revolução na moral e na política.

\section{Intepretaçáo de Donald Rutheford}




\subsection{Acquiescentia in se ipso}

As definiçóes de amor e ódio afirmam que a causa dessas emoçóes são externas, mas isso não é necessário, pelo menos não no caso do amor. Quando a mente humana é consciente de si como causa do aumento em sua própria perfeiçáo, por ter atuado de sua forma específica, ou seja, exercendo o entendimento, é afetada de um tipo de amor próprio, de uma alegria acompanhada da ideia de si como causa dessa alegria. É a acquiescentia in se ipso ou satisfação consigo mesmo (Def. Aff. 25), que depende, portanto, da reflexão adequada sobre um conhecimento adequado que sempre o acompanha (segundo um princípio epistemológico espinosista).

\subsection{Acquiescentia animi}

Para Rutheford, Espinosa, no final da Parte IV (IVapp.4), indica que, para obter a maior satisfação, "não basta simplesmente viver de acordo com a razão de qualquer jeito ordinário", mas é preciso "aperfeiçoar nosso intelecto pelo conhecimento de Deus" (Idem). E isso trará, não mais a acquiescentia in se ipso, mas a acquiescentia animi, que é a maior felicidade para o homem (Parte V) . Mas, segundo IVP52s, a satisfação consigo mesmo não era o máximo que podíamos esperar? Como Espinosa vai esclarecer, o autor responde, tratam-se do mesmo tipo de afeto, de uma alegria que surge da consideração de si e do poder de agir, e diferem-se em relaçáo ao gênero de conhecimento a que estáo ligados: $2^{\circ}$ ou $3^{\circ}$ gênero.

O $3^{\circ}$ gênero supóe que a mente seja eterna, e isso parece indicar que a alegria que surge da consciência da mente de ter esse gênero de conhecimento é igualmente eterna. Porém, como pelo conhecimento de Deus chego a uma consideração de mim e de meu poder de agir e por que dele depende minha plena satisfação?

[A] dependência necessária de todas as coisas em Deus é a maior coisa que pode ser compreendida, e porque, através do $3^{o}$ gênero de conhecimento, compreendemos tal dependência diretamente, sem mediaçáo de outras ideias, esse conhecimento é fonte da maior potência da mente e, entáo, de sua maior satisfação (RUTHEFORD, 1999, 460p). 


\subsection{Eternidade da mente}

Segundo o autor, a doutrina da eternidade da mente é "um componente integral da hipótese de Espinosa sobre o $3^{\circ}$ gênero” (Idem). Se por este não se conhece as coisas enquanto "existindo em relação a um certo tempo e espaço", mas enquanto "contidas em Deus e seguindo da necessidade da natureza divina" (VP29s); não enquanto surgem a partir da modificação finita de um atributo de Deus, mas de sua natureza absoluta (IP28), o conhecimento que dele surge é eterno. Pela lei da homologia, para ser capaz de tal conhecimento, a mente precisa ser necessária e igualmente eterna.

Contudo, não parece que a mente seja capaz de um conhecimento eterno, pois fora definida como uma ideia cujo objeto é o corpo existente (IIP13), o que só a possibilitaria de conceber a duração e as coisas em relaçáo ao tempo (VP29d). Para ser de outro modo, precisaria poder ser concebida de outra maneira, como tendo outro objeto: é isso que proporia Espinosa, ao conceber a mente em sua essência, cuja representação é a essência do corpo humano. Enquanto é eterna, a mente pode conceber as coisas sub species aeternitatis (VP31).

E se essa mente que conhece pelo $3^{\circ}$ gênero de conhecimento é concebida sub species aeternitatis, ela é concebida através da essência de Deus, ou enquanto através da essência de Deus envolve existência, segundo a VP30, porque Deus é a causa imanente da mente. Assim, Deus é igualmente causa do $3^{\circ}$ gênero e da alegria que surge da consciência de tê-lo. Por definiçáo, o amor é uma alegria acompanhada da ideia de uma causa externa. Logo, a mente dirige a Deus um amor "náo enquanto o imaginamos como presente (por P29), mas enquanto compreendemos Deus como eterno" (VP32). Pela mesma lei da homologia, esse amor intelectual a Deus é necessariamente eterno. Desse modo, não pode surgir de nenhum aumento de perfeiçãa, e sim, de um estado de perfeição eterno, que Espinosa chama de beatitude (no qual a mente sempre estaria, mas sem ter consciência).

Do $3^{\circ}$ gênero, que é eterno, segue a acquiescentia, uma alegria vinda da consciência da mente sobre si mesma e seu poder de agir, que também deve ser eterna.

Portanto, Rutheford vê que a mente humana é:

identificada com uma parte do intelecto eterno e infinito de Deus (VP40s), parte que inclui ideias adequadas de sua dependência eterna 
em Deus e os afetos - de beatitude, amor ao divino e satisfaçáo da mente - associados com essas ideias (Idem, 465).

\subsection{A Salvaçáo do Filósofo}

A salvação do filósofo ainda poderia ocorrer nesta terra, se a acquiescentia animi está necessariamente ligada à satisfação de uma mente eterna? Como salienta Rutheford, a última frase da Ética parece indicar que sim: "mesmo que pareça muito difícil o caminho, ainda pode ser encontrado" (VP42). A salvaçáo seria um episódio decisivo na vida do filósofo, conquistada em um dado momento, através de seus esforços para aperfeiçoar seu entendimento por meio do $3^{\circ}$ gênero de conhecimento, e durável apenas enquanto sustentasse tal modalidade cognoscitiva.

Mas como poderia se sustentar que a acquiescentia animi é assim conquistada, se ela não possui nenhuma relação com o tempo? Posições que vão nesse sentido "importam noçóes temporais estrangeiras à visão de Espinosa sobre a salvação” (Idem, 465).

Contudo, no Curto Tratado, Espinosa diz que a mente, ao alcançar a salvação, passa por um "renascimento", entrando na eternidade e deixando a duração (Idem, 466p).

A teoria da Ética, porém, seria mais complexa, ao assumir que a mente é uma ideia do corpo. Em primeiro lugar, essa tese daria à mente uma grande complexidade, pois a faz corresponder através de ideias ao grande número de "indivíduos altamente compostos" que compóem o corpo (IIP15). Além disso, como "a ideia de uma coisa singular existente em ato envolve necessariamente tanto a essência quanto a existência dessa coisa" (IIP45), a mente precisaria, além de envolver na ideia do corpo a ideia de sua duração, abranger também a ideia de sua essência. Como a essência está sob a espécie da eternidade e ideia que dela temos é igualmente eterna, conclui-se que a mente é composta por dois tipos de ideias, em referência ao tempo: uma que incorpora uma representação da duração; outra, que não.

De tal forma fracionada, como pode a alma preservar sua unidade? Pela sua própria definiçãa, que depende do corpo. Se o corpo mantém sua unidade, através de uma constância entre movimento e repouso, mantida por seu esforço enquanto não é ultrapassado pelas causas exteriores, a alma como sua ideia vai permanecer. Em paralelo a tal "razão" do corpo, a mente é sustentada por uma sucessão de ideias mantida por sua própria potência, independentemente se 
as ideias são adequadas, seguindo apenas de sua natureza, ou se são inadequadas, seguindo em conjunção com a natureza de outras mentes (IIP11C e IIIP9d).

Como Espinosa explica em IIP44 e em seus corolários, as primeiras são ideias em que as coisas sáo representadas como necessárias e eternas; as últimas, ideias em que as coisas são representadas como contingentes e temporais. Contudo, em ambos os casos, as ideias seguem (inteira ou parcialmente) da mesma mente, que permanece por virtude de sua essência (Idem, 468p).

Assim, não haveria por que contestar que a mesma mente permaneça antes e depois de assumir o $3^{\text {o }}$ gênero de conhecimento, pois a aquisiçáo desse conhecimento representa "uma mudança simplesmente na determinação das ideias e não em seu modo de existência (de duracional para não-duracional)" (Idem).

Defender isso, entretanto, não quer dizer que haja uma continuidade psicológica, ou uma consciência de si mesmo perseverando. Ora, a consciência de si mesmo depende de a alma ter a ideia cujo objeto é si mesma ou ter ideias que a constituem (IIP21s). Mas a alma é ideia do corpo e as ideias que a constituem representam as afecçôes desse corpo. Logo, a consciência de si depende de uma existência corporal e de suas variadas percepçóes, que estão unidas pela memória (IIP18s).

Sobre esse autoconhecimento, Espinosa "está mais concentrado em dizer que é necessariamente inadequado" (Idem). Ora, a mente humana náo conhece o corpo em si mesmo, pois a ideia que tem dele existe em Deus "enquanto é considerado como afetado de outra ideia singular” (IIP19), conhecendo apenas o efeito e não a causa. Ademais, ao longo de sua duração, o corpo é ainda afetado por diversos outros corpos, pelos quais é "como que continuamente regenerado" (IIP19). Sua ideia passa, assim, a existir em Deus "enquanto é considerado como afetado das ideias de muitas coisas singulares" (IIP19), distanciando-se mais ainda da causa pela soma de efeitos.

Para ter um conhecimento adequado de si mesma como ideia de um corpo que dura, a mente deveria, per impossibile, conhecer a si mesma apenas na medida em que a ideia do corpo está contida no intelecto infinito, e não enquanto essa ideia constitui a mente humana (Idem, 468-469p). 
Essa hipótese impossível parece ser o que é proposto no meio da Parte V: um experimento mental de considerar a mente separada do corpo da duraçáo, para poder concebê-la apenas formada por ideias adequadas, eterna, no intelecto infinito. Mas seria um erro pensar que Espinosa está dizendo que a mente adquiriria uma existência eterna de algum modo. Concentrando-se em nossas ideias adequadas, nas essências das coisas, Espinosa "está abstraindo da natureza da mente como um todo, a fim de isolar aquelas ideias que formam a base de sua grande satisfação” (Idem, 470p).

Rutheford considera razoável pensar que, ao lado das ideias adequadas, a mente, enquanto considerada como um todo, também abarque uma ideia de si mesma como um indivíduo perseverante na duração. Logo, ao conhecer, a mente poderia usufruir de uma acquiescentia in se ipso eterna, tendo ainda consciência de sua duração.

Mas isso ainda não seria suficiente para que obtenha a salvação, que depende da aquiescentia animi. Esse afeto supóe que a mente conheça a si mesma como causa adequada do $3^{0}$ gênero, o que só é possível se se considerar como eterna (VP31), conforme o conhecimento adequado de si mesma depende de ter em conta a ideia de sua essência. Pelo $3^{\circ}$ gênero, concebe que é um poder de agir que resulta necessária e eternamente da essência infinita de Deus. Logo, relaciona "seu conhecimento intuitivo a um só tempo a seu poder e ao poder de Deus, produzindo tanto satisfação da mente, quanto amor intelectual a Deus (VP36s)”.

Rutherford pode distinguir melhor agora os dois afetos. Acima da diferença entre os gêneros de conhecimento com que estão relacionados, Espinosa compreenderia que ter um, ou outro, depende de considerar ou náo a mente como eterna, abstraída do corpo da duraçáo. Considerando a mente como um todo, abrangendo as ideias inadequadas, a mente só pode ter acquiescentia in se ipso, pois terá consciência de si e de seu poder de agir, mas sem conseguir conceber o que é esse poder, que deriva, em último caso, de Deus.

Mas como o homem consideraria, por outro lado, a mente como eterna? Um tal "renascimento" (expressáo do Curto Tratado que o autor destaca) náo parece ser possível; mesmo que fosse, perderia de vista a continuidade psicológica, que parece trazer coerência à salvação do filósofo. Assim, Rutherford dá novo peso à afirmação de a acquiescentia in se ipso ser "realmente a maior que coisa que podemos esperar": seria a alegria do filósofo que, "pelo menos em alguns momentos, é consciente de si como tendo o $3^{\circ}$ gênero, mas logo falha em identificar a si mesmo 
como causa adequada desse conhecimento, preservando a noção de ser a mente de um corpo perecível” (Idem, 473p). Ainda assim, sua mente teria sua maior parte composta por ideias adequadas - e é para essa conquista que Espinosa estaria engajado na Parte V. Para Rutherford, sem essa ideia do corpo como um indivíduo temporalmente durável, onde reside "o mais profundo senso de nossa identidade pessoal" (Idem), seria difícil dizer que o filósofo atingiria a salvação prometida pela Ética.

\section{Conclusão}

Chegando ao final de dois caminhos diferentes, propostos respectivamente por Nadler e Rutherford, podemos traçar as devidas aproximações e distanciamentos.

Ambos concordam que a pessoa humana não continua a existir depois da morte, visto que a pessoalidade está ligada à memória, àqueles momentos de que eu me recordo estar consciente. Tal tese poderia parecer óbvia pelo texto de Espinosa, mas, como vimos no Panorama, alguns autores defenderam o contrário.

Dessa forma, enquanto os dois estáo de acordo que neste mundo "sentimos e experimentamos que somos eternos", seria preciso saber como cada "eu” durável acessa a eternidade. Ainda que Nadler diga que é a sua essência eterna que permite esse acesso ao homem, um elo de coesão entre o modo do Pensamento e o modo da Extensão não é proposto.

Depois de esmiuçar bem o assunto da eternidade da mente, Nadler propóe que o que permanece depois da morte são as ideias adequadas, que retornam a Deus. Essas que comporiam a melhor parte da mente. Afinal, ao conhecer melhor Deus pelo conhecimento adequado das coisas (prop. 25), expressamos em parte o conhecimento perfeito que Deus tem de si mesmo, “participando" dele. Sem dúvida, é uma tese de matiz averroísta que inicialmente parecia ter sido deixada de lado. Rutheford, por seu lado, não se pronuncia a respeito do "além". E em todo esse contexto queremos indagar: se toda ideia adequada, como qualquer ideia, supóe reflexáo - pelo que nos parece, por sua natureza, de ser uma modificação do Pensamento, dentro de um nexo formado por outras ideias que a refletem, e não por qualquer função própria do homem - e a 
mente é uma ideia adequada, como não haveria alguma consciência depois da morte? Nessa direção, por incrível que pareça, encarminhar-nos-íamos à tese inicialmente desbaratada de que Espinosa teria defendido a identidade pessoal pós-morte.

A respeito da investigaçáo afetiva de Rutheford, a lei da homologia parece que, ao cabo, não funcionou. Ter alguma percepção do eterno não nos levaria a ser eterno. E não adianta ter uma acquiescentia animi sem consciência. Essa satisfação estaria, pois, mais próxima de ser um "estado psicológico que persevera no tempo", algo que o autor havia considerado estar em desacordo com o texto da Ética. Com uma parte inicial, talvez. Mas náo com o todo.

Diante de tais apontamentos, de não permanecermos na eternidade, não se afiguraria muita esperança para o homem que buscava salvaçáo. Mas é preciso ver que, excluindo a vida pessoal depois da morte, Espinosa nos tira o fardo da condenaçáo eterna, e mesmo da interesseira busca pelo céu. Transfere o benefício das "boas obras" para o aqui e agora, dentro da dinâmica do conatus. A felicidade está neste mundo, no "século". Ainda que seja uma aventura individual, seguir a vida da razão traria vantagens para a comunidade, uma vez que o sábio romperia com ciclos de violência e se entregaria para ser amado. Mas a sabedoria é um caminho estreito. Há salvação para o ignorante?

\section{Referências Bibliográficas}

BENNETT, Jonathan. A Study of Spinoza's Ethics. Indianapolis: Hackett Publishing Company, 1984.

DELEUZE, Gilles. Cursos sobre Spinoza (Vincennes 1978-1981). Fortaleza: UECE, 2010. . Espinosa-Filosofia Prática São Paulo: Escuta, 2002.

GLEIZER, Marcos A. Espinosa e a afetividade humana. Rio de Janeiro: Zahar, 2005.

ITOKAZU, Ericka M. Tempo, duração e eternidade na filosofia de Espinosa. Dissertação em Filosofia. Sáo Paulo: Faculdade de Filosofia, Letras e Ciências Humanas da Universidade de São Paulo. 
MATHERON, Alexandre. Individu et communauté chez Spinoza. Paris : Minuit, 1988.

MOREAU, Joseph. Espinosa e o espinosismo. Lisboa: Edições 70, 1982.

NADLER, Steven. Eternity and Immortality in Spinoza's Ethics. In: Midwest Studies in Philosophy, XXVI, 2002, pp. 224-244. Press, 2001a. . Spinoza's Heresy. Immmortality and the Jewish Mind. Oxford: Clarendon

PINHEIRO, Ulysses. A heresia oculta de Espinosa. In: Revista Analytica. No prelo. 2011.

RAMOND, Charles. Vocabulário de Espinosa. São Paulo: Martins Fontes, 2010.

ROVIGHI, Sofia V. História da Filosofia Moderna. São Paulo: Loyola, 2006.

RUTHERFORD, Donald. Salvation as a State of Mind: The Place of Acquiescentia in Spinoza's Ethics. In: British Journal for the History of Philosophy, 7 (3), 1999, pp. 447473.

SPINOZA, Benedictus de. Ética. Tradução e notas de Tomaz Tadeu. Belo Horizonte: Autêntica Editora, $20082^{\text {a }}$ ed. 